\title{
Impact of Post- Deposition Heat Treatment on the Morphology and Optical Properties of Zinc Oxide (ZnO) Thin Film Prepared by Spin-Coating Technique
}

\author{
Sunday Wilson Balogun ${ }^{1,}$, Yekini Kolawole Sanusi ${ }^{1,2}$, Adebayo Olaniyi Aina ${ }^{1}$ \\ ${ }^{1}$ Department of Physics and Materials Science, Kwara State University Malete, Ilorin, Nigeria \\ ${ }^{2}$ Department of Pure and Applied Physics, Ladoke Akintola University of Technology, Ogbomoso, Nigeria
}

Email address:

sbalogun94@gmail.com (S. W. Balogun), sanusiyk33@gmail.com (Y. K. Sanusi), adebayo.aina@gmail.com (A. O. Aina)

*Corresponding author

\section{To cite this article:}

Sunday Wilson Balogun, Yekini Kolawole Sanusi, Adebayo Olaniyi Aina. Impact of Post- Deposition Heat Treatment on the Morphology and Optical Properties of Zinc Oxide (ZnO) Thin Film Prepared by Spin-Coating Technique. Journal of Photonic Materials and Technology. Vol. 3, No. 3, 2017, pp. 20-28. doi: 10.11648/j.jmpt.20170303.11

Received: November 19, 2017; Accepted: December 4, 2017; Published: December 26, 2017

\begin{abstract}
This research work examines the structural and optical properties of $\mathrm{ZnO}$ thin films. Deposition were done by spin coating of solution of Zinc oxide onto pre-cleaned glass substrate at $4000 \mathrm{rpm}$ for $30 \mathrm{sec}$ using spin-coater under ambient condition at room temperature in order to form desired thickness of the film on the substrate. Post- deposition thermal annealing at different range of temperatures from $150^{\circ} \mathrm{C}$ to $600^{\circ} \mathrm{C}$ with steps of $50^{\circ} \mathrm{C}$ was carried out on the samples. The impact of thermal annealing on optical properties of the deposited thin film was investigated using UV-VIS spectrophotometer and scanning Electron Microscope for the morphology. The optical transmittance, reflectance, absorbance were recorded which was used to evaluate the optical band gap of Zinc oxide. Observation shows that band gap energy reduces as annealing temperature is increased from $150^{\circ} \mathrm{C}$ to $600^{\circ} \mathrm{C}$. Observation made on the morphology using SEM model ASPEX 3020 showed that as the temperature increases the surface of the sample roughness increases. It was deduced that as the annealing temperature is increased the surface roughness increases. This may be due to increase in grain size with increase in annealing temperature. The band gap energy decreases as the annealing temperature increases.
\end{abstract}

Keywords: Spin-Coating, Thermal Annealing, Zinc Oxide, Morphology, Optical Properties

\section{Introduction}

Zinc oxide $(\mathrm{ZnO})$ is an important semiconductor material that has its found application in organic electronics such as solar cells and optoelectronics to mention but a few [1]. The techniques that can be used to deposit $\mathrm{ZnO}$ on glass substrate includes Chemical Vapor Deposition (CVB), Spray pyrolysis, Thermal vacuum Deposition, Sputtering and the last but not the least Spin- coating [2]. Zinc oxide is an inexpensive ntype semiconductor which can be used as electron transporting layer in solar cells because it has high thermal and mechanical stability at room temperature coupled with chemical stability. It has broad range of radiation absorption and high photo stability. Zinc oxide $(\mathrm{ZnO})$ is used as a heterogeneous catalyst, have a high catalytic activity, nontoxic, insoluble, and also a cheap catalyst [3 -4] which is an important n-type [5-7] semiconductor. $\mathrm{ZnO}$ is not only a material of particular interest because of its unique optical and electronic properties, but also it has some characteristics that include the following: (a) wide-band gap semiconductor [3-18], (b) large exaction binding energy of $60 \mathrm{MeV}$ [5-7, 10, $12,13,19-20]$. The interest in $\mathrm{ZnO}$ is as a result of its high abundance and the availability of potentially high quality low cost substrate layers of transparent $\mathrm{ZnO}$ films on which electronic processes solar cells and flat panel displays occur [21-30].

In this research work spin-coating method was employed to deposit the $\mathrm{ZnO}$ on the pre cleaned glass substrate, because it possesses several advantages, such a low temperature processing, easy coating of large area, and being suitable for preparation of porous films and homogenous multi component oxide films. The spin-coating conventional 
techniques involved the placing of pre- cleaned substrate on the stub of the spin- coater model laurel WS-650Hz-23NPP, set the program, dispense liquid, run the program under ambient condition at room temperature. Deposition was done by spin coating of solution of ZNO onto pre-cleaned glass substrate at $4000 \mathrm{rpm}$ for $30 \mathrm{sec}$ using spin-coater under ambient condition at room temperature in order to form $35 \mathrm{~nm}$ thickness of the film on the substrate. The process of coating to drying was repeated to obtain the desired thickness of the film. Ethanol was used to dissolve $\mathrm{ZnO}$ powder because it evaporates in lesser rate than Methanol and also have no characteristic absorption and emission in the visible range. $\mathrm{ZnO}$ powder dissolved in Ethanol upon sonication for 3 hrs for homogeneous mixture. The effect of thermal annealing on the morphological properties and optical properties of Zno thin films was studied using scanning electron microscope (SEM) model ASPEX 3020 and UVVIS spectrophotometer Avantes model Avalight-DH-5-BAL.

\section{Experimental Procedures}

\subsection{Materials}

The materials used in this experiment were purchased from Sigma-Aldrich namely, ZnO powder and Glass slides.

\subsection{Methods}

\subsubsection{ZnO Sample Solution Preparation}

$1 \mathrm{ml}$ Ethanol solvent was added into $81.38 \mathrm{mg}$ of $\mathrm{ZnO}$ powder from Sigma Aldrich. The solution then underwent ageing process for 3 hours upon sonication at room temperature without heat to allow homogeneous mixture and $\mathrm{ZnO}$ powder to fully dilute into solvent. Ethanol was chosen as a solvent because it has no characteristic absorption and emission in the visible range.

\subsubsection{Substrate Preparation}

Clean rectangular glass slides of dimension $25.4 \mathrm{~mm}$ by $76.2 \mathrm{~mm}$ were used as substrates. The substrates were washed with detergent solution for 10 to 15 minutes and ultrasonically rinsed in water bath distilled water for 15 minutes at $30^{\circ} \mathrm{C}$. The substrate was cleaned with Isopropanol acid [IPA] in ultrasonic bath for 15 minutes at $30^{\circ} \mathrm{C}$ and was blow-dried in Nitrogen environment.

\subsubsection{Deposition of ZNO on the Substrate Using Spin-Coater}

Place pre- cleaned substrate on the stub of the spin- coater Model WS-650MZ-23NPP, set the program, dispense liquid, run the program that is drop onto substrate, wait for several moments to enable solution to seep. Deposition was done by spin coating of solution of $\mathrm{ZnO}$ onto pre-cleaned glass substrate at $4000 \mathrm{rpm}$ for $30 \mathrm{sec}$ using spin-coater under ambient condition at room temperature in order to form $35 \mathrm{~nm}$ thickness of the film on the substrate The process of coating to drying was repeated to obtain the desired thickness of the film.. The system rotates first at low speed to spread the liquid then at high speed to dry. This technique is cheaper and easier to use, it allows for uniform deposition unto flat substrate. Pre-heat deposited samples at $150^{\circ} \mathrm{C}$ for $1 \mathrm{hr}$ then slow cooling at room temperature to pyrolyze any unwanted ingredient other than $\mathrm{ZnO}$.

\subsection{Samples Characterization}

The pre-heat deposited samples were annealed at different temperatures range from $150^{\circ} \mathrm{C}$ to $600^{\circ} \mathrm{C}$ for 60 minutes at step size of $50^{\circ} \mathrm{C}$ using Carbolite tubular furnance model Srw 21-501042 Type-CT17 and quenched at room temperature in Argon gas. One sample was untreated which is designated as control. Annealing is a heat treatment, involves heating a material to above its critical temperature, maintain a suitable temperature and then cooling. It can induce ductility, soften material, relieve internal stresses, refine structure by making it homogeneous and improve cold working properties. Optical transmittance and reflectance was measured using UV-VIS Avantes spectrophotometer model Avalight-DH-5BAL for wavelength 200 and $1000 \mathrm{~nm}$. All samples were characterized to determine the optical spectrum for different annealing temperatures.

Mathematically $\mathrm{A}+\mathrm{R}+\mathrm{T}=1, \mathrm{~A}$ is the absorbance, $\mathrm{R}$ is the reflectance and $\mathrm{T}$ is the transmittance. To convert between the absorbance and transmittance, use the equation (1) below,

$$
\text { Absorbance }(\mathrm{A})=2-\log _{10}(\% \mathrm{~T}) \text {. }
$$

The absorption coefficient of thin film is calculated from the formula (2) [31]

$$
\alpha=2.303(\mathrm{~A} / \mathrm{t})
$$

Where, $\mathrm{A}$ is absorbance and $\mathrm{t}$ is the thickness [32]

The absorption coefficient $\alpha$ and the extinction coefficient $\mathrm{k}$ are related by the formula (3)

$$
\mathrm{K}=\alpha \lambda / 4 \pi
$$

Where, $\lambda$ is the wavelength. The variation of extinction coefficient $\mathrm{k}$ with wavelength is shown in figure 4 . Zno is a direct -gap semiconductor. The optical band gap energy Eg and absorption coefficient $\alpha$ is related by the equation (4) [33]

$$
(\alpha h v)^{2}=\mathrm{hv}-\mathrm{Eg}
$$

Where, $\alpha$ is the absorption coefficient and hv is the incident photon energy. Band Gap Energy $(E)=h \mathrm{c} / \lambda$ where $\mathrm{h}=$ planks constant $=6.626 \times 10^{-34}$ joules sec. $\mathrm{C}=$ speed of light $=3.0 \times 10^{8}$ meter/sec. where $1 \mathrm{ev}=1.6 \times 10^{-19}$ joules (conversion factor). ]. For calculation of the optical band gap of films, the curve of $(\alpha h v)^{2}$ vs. ho was plotted. The energy band gap was obtained from straight line plot of $(\alpha h v)^{2 /}$ vs. ho by extrapolating of the line to base line in figure 7 to figure 12

\subsection{Optical Characterization}

\subsubsection{Transmittance}

The optical transmittance of the samples was measured with an Avantes UV-VIS spectrophotometer. The spectrophotometer operates by providing a light source 
towards an aperture using an optical fiber and uses another aperture to measure the amount of light transmitted or reflected by the sample under test. Optical transmittance measurement was recorded with spectrophotometer in the wavelength between $200 \mathrm{~nm}$ and $900 \mathrm{~nm}$. The transmittance spectrum is as shown in figure 1 to figure 3 . The control is the untreated or un-annealed sample. The absorption spectra for $\mathrm{ZnO}$ thin films annealed at different temperatures is as shown in figure 4 It is deduced that as the annealing temperature increases there is increase in absorption of photon energy. It also shows that transmission increases as the wavelength increases and decreases with increases in annealing temperature. As the annealing temperature increases the absorption increases and as the wavelength increases the absorption decreases.

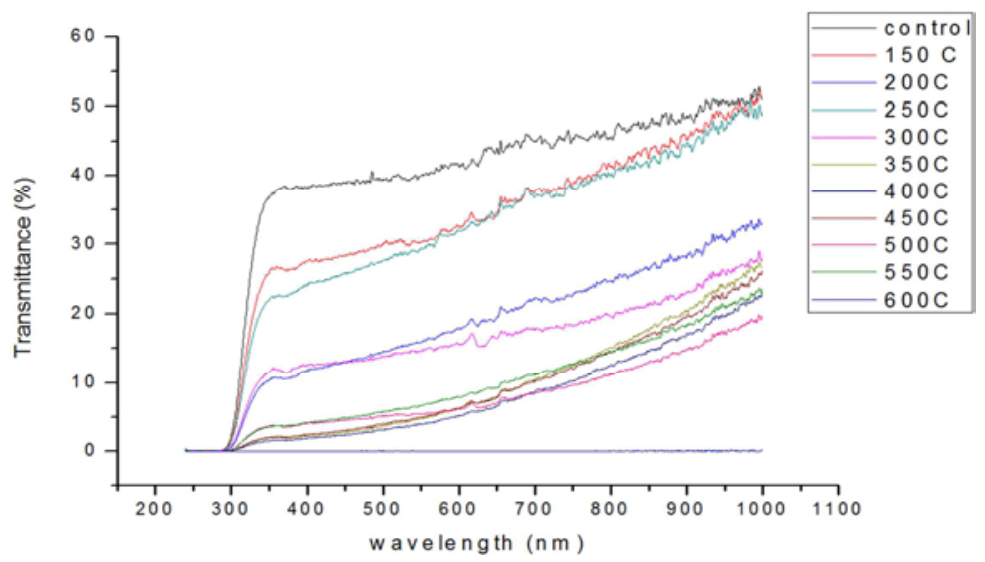

Figure 1. Transmittance versus wavelength graph at different annealing temperature.

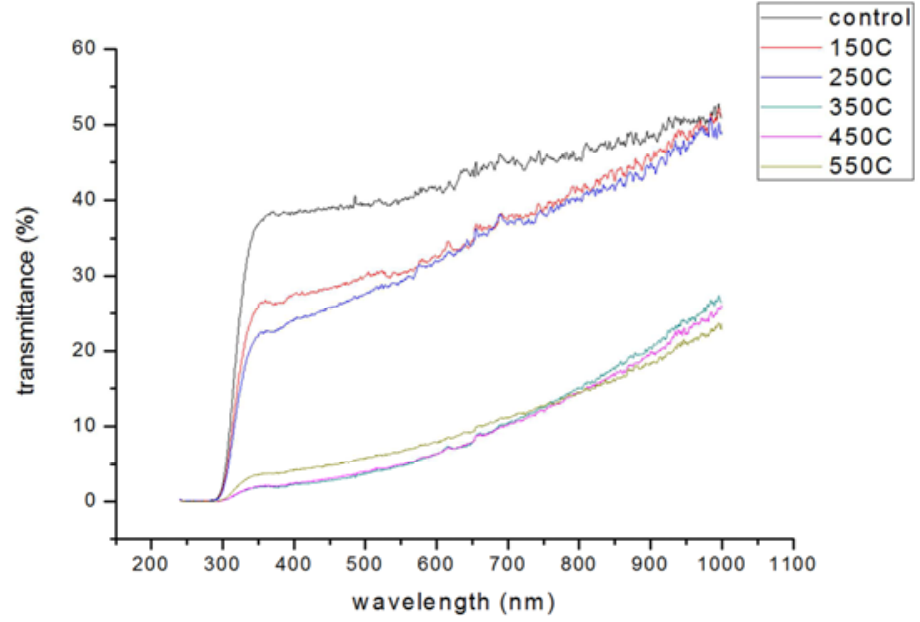

Figure 2. Transmittance graph of selected temperatures.

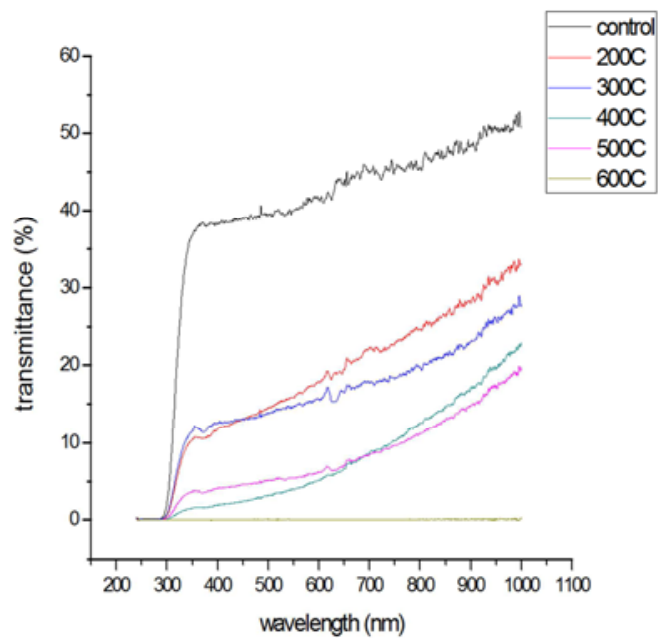

Figure 3. Transmittance versus wavelength graph of selected temperatures.

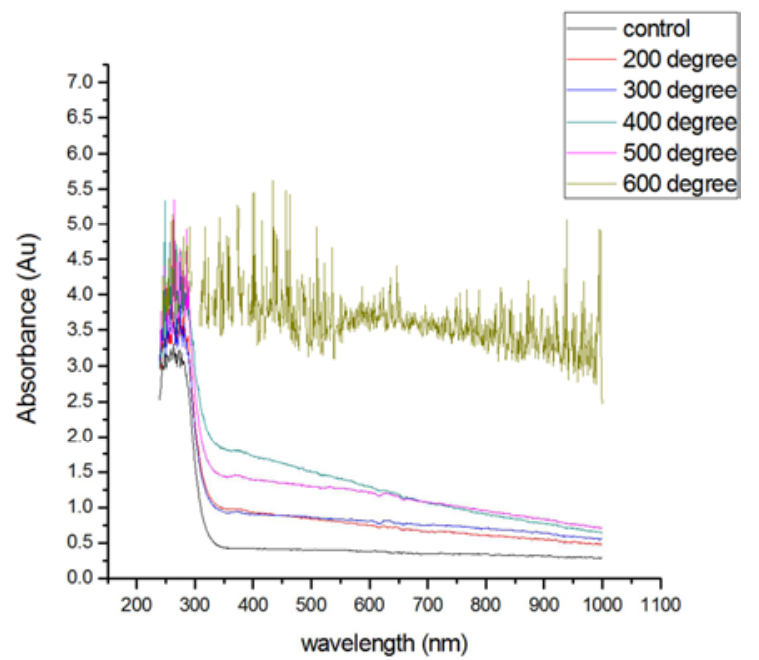

Figure 4. Absorbance of $\mathrm{ZnO}$ thin films annealed at different temperatures. 


\subsubsection{Absorption Coefficient}

The absorption coefficient of $\mathrm{ZnO}$ thin film is calculated using this formula.

$$
\alpha=2.303(\mathrm{~A} / \mathrm{t})
$$

Where $\mathrm{A}$ is the absorbance, $\mathrm{t}$ is the thickness. Extinction

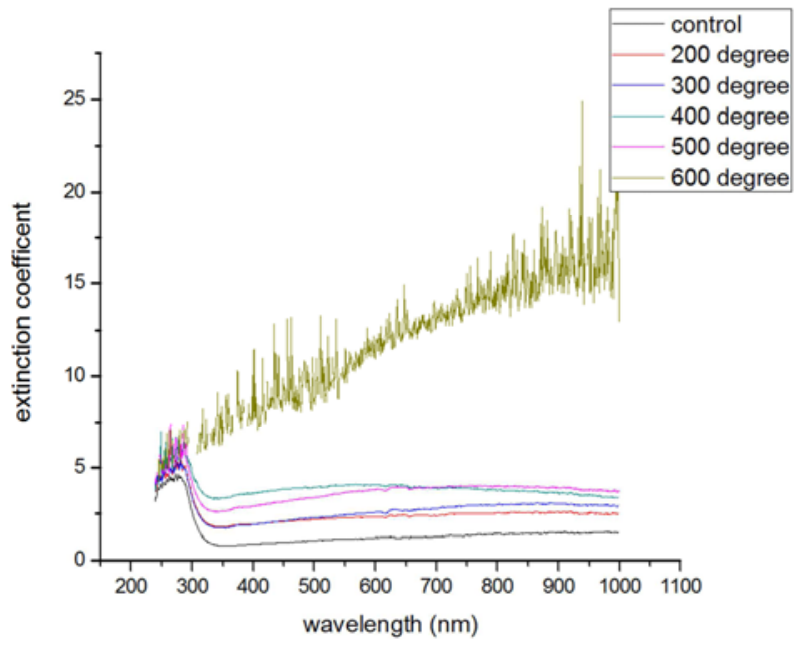

Figure 5. Extinction coefficient graph versus wavelength for zno films annealed at different temperatures.

\subsubsection{Reflectance}

The graph of $\mathrm{ZnO}$ thin films is as shown in figure 6.

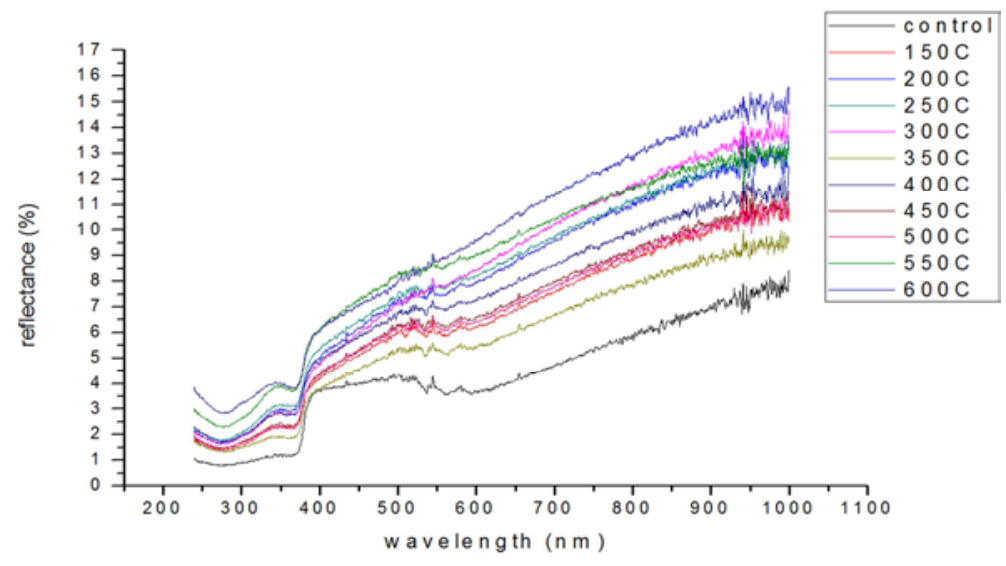

Figure 6. Plot of reflectance versus wavelength graph.

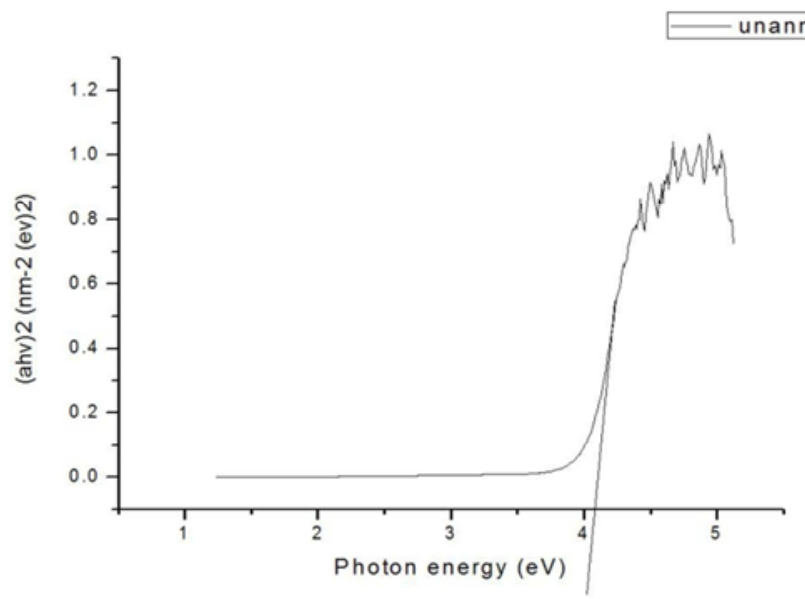

Figure 7. Band gap energy graph of un-annealed $\mathrm{ZnO}$ thin film.

$$
\mathrm{K}=2.303(\mathrm{~A} / \mathrm{t}) \lambda / 4 \pi
$$

The graph of extinction coefficient versus wavelength is shown in figure 5 . 


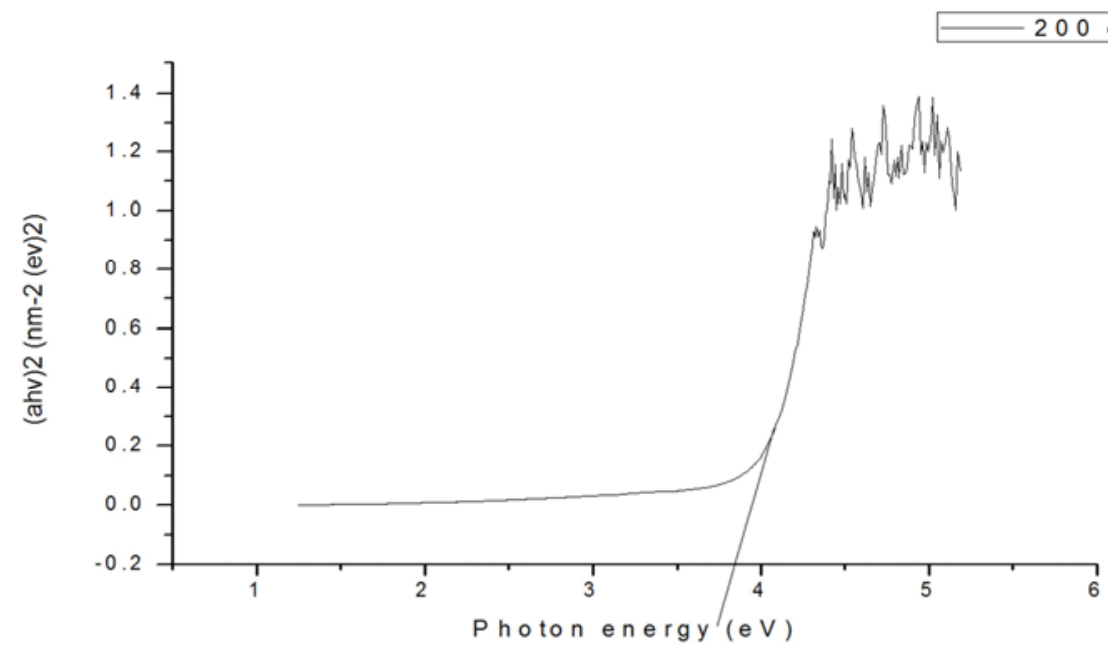

Figure 8. Band gap energy of $\mathrm{ZnO}$ thin film annealed at $200^{\circ} \mathrm{C}$.

$\square 300$ degree

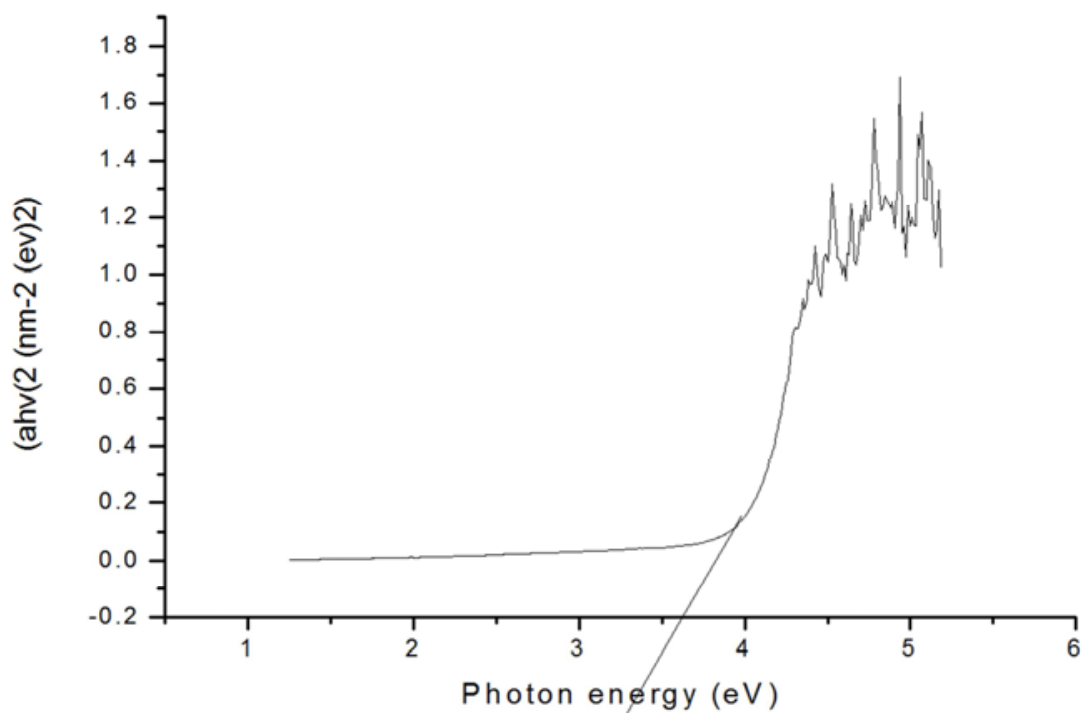

Figure 9. Band gap energy of $\mathrm{ZnO}$ thin film annealed at $300^{\circ} \mathrm{C}$.

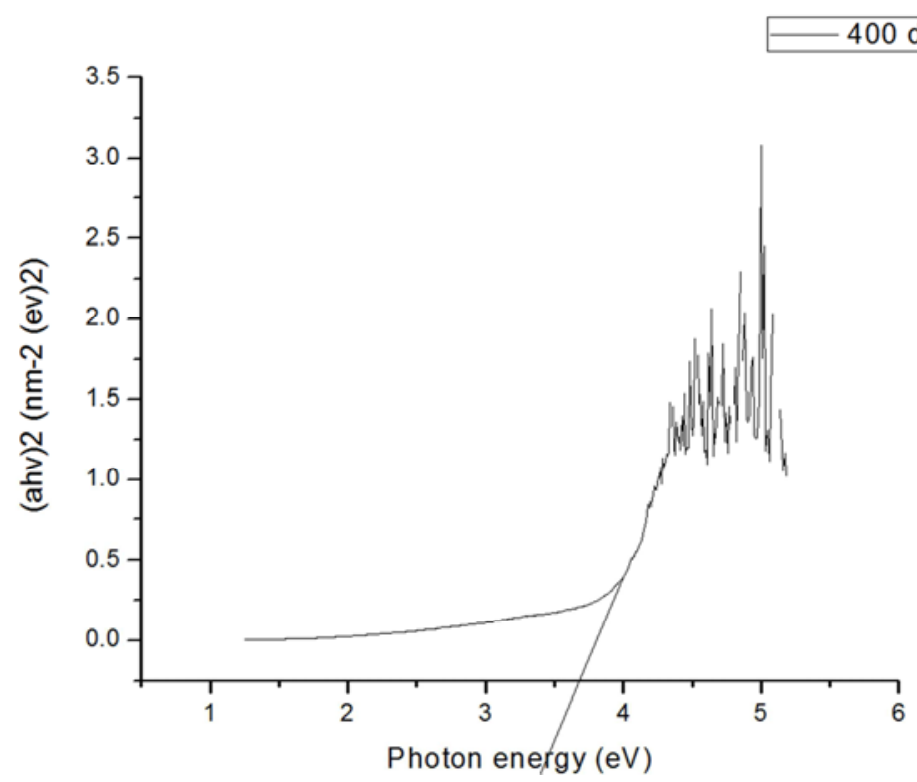

Figure 10. Band gap energy of $\mathrm{ZnO}$ thin film annealed at $400^{\circ} \mathrm{C}$. 


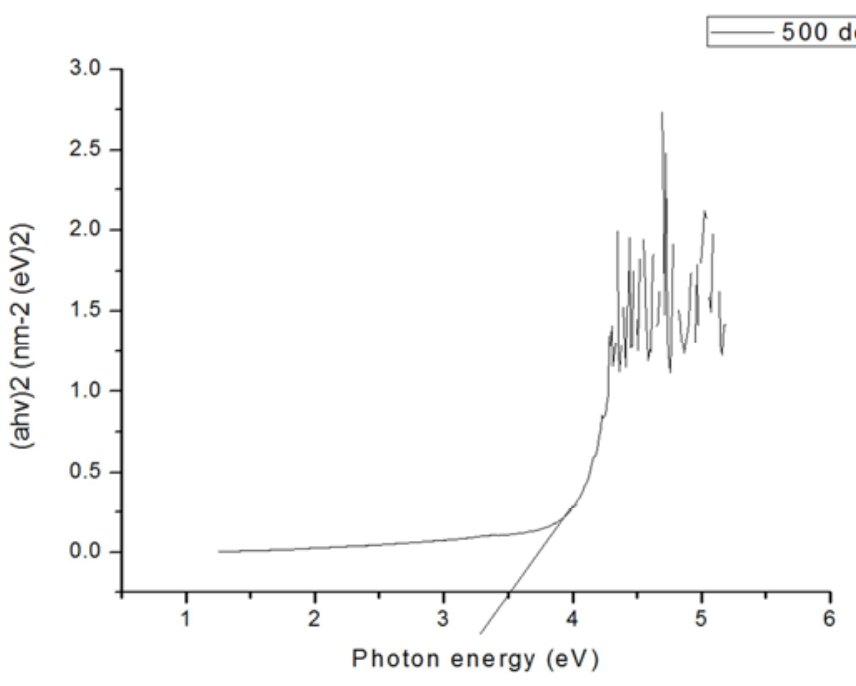

Figure 11. Band gap energy of $\mathrm{ZnO}$ thin film annealed at $500^{\circ} \mathrm{C}$.

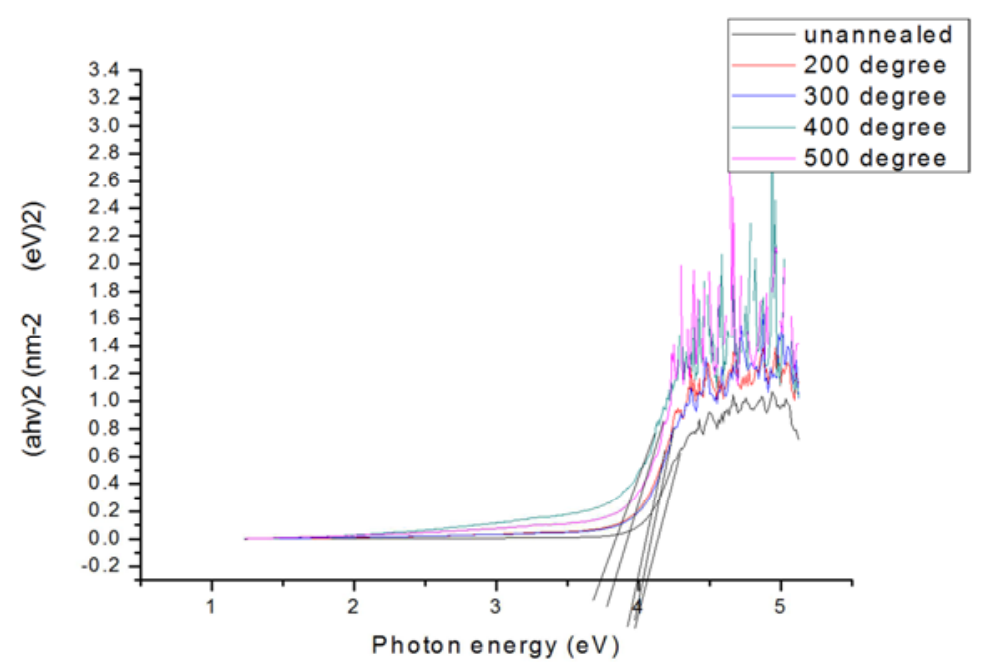

Figure 12. Band gap energy of $\mathrm{ZnO}$ thin films annealed at different varying Temperatures.

\subsection{Morphological Characterization}

Scanning Electron Microscope observation (SEM) model ASPEX 3020.

Scanning electron microscope (SEM) was employed to image the surface of the samples. All samples were appropriately cut to a size that can fit on the specimen stub of the SEM machine. SEM provides a useful means for investigating the morphological properties of the samples surface at desired magnification. To analyze the surface behavior of the sample. SEM morphology study of samples were carried out. Figure 13 to Figure 17 shows images of the sample at different temperature ranging from $150^{\circ} \mathrm{C}$ to $550^{\circ} \mathrm{C}$ in order to compare their surface morphologies with respect to the temperature variation. It was deduced that as the annealing temperature is increased the surface roughness increases. This may be due to increase in grain size with increase in annealing temperature. Figure 13 to figure 17 shows the morphological images at $150^{\circ} \mathrm{C}, 250^{\circ} \mathrm{C}, 350^{\circ} \mathrm{C}$, $450^{\circ} \mathrm{C}, 550^{\circ} \mathrm{C}$

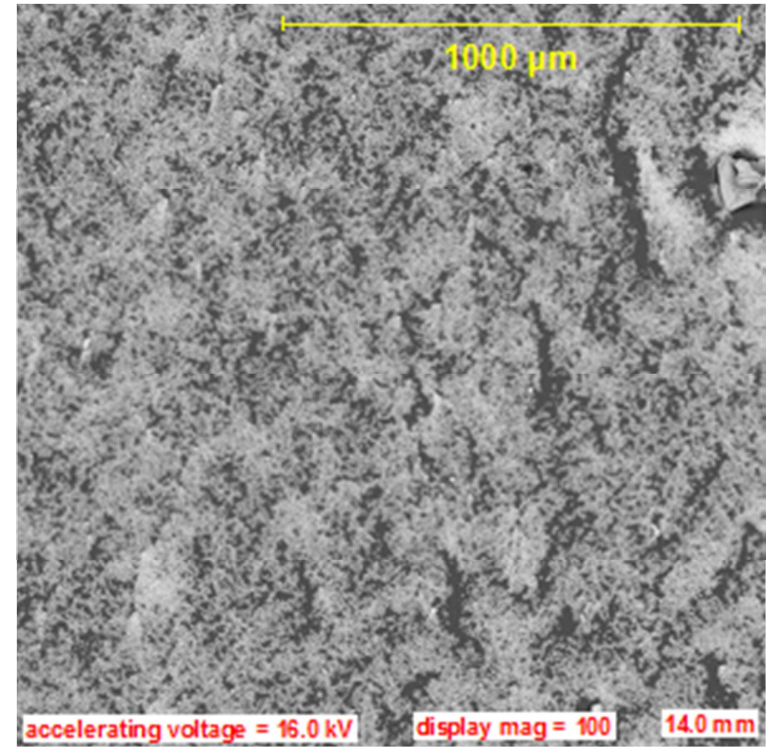

Figure 13. SEM image of ZNO film annealed at $150^{\circ} \mathrm{C}$. 


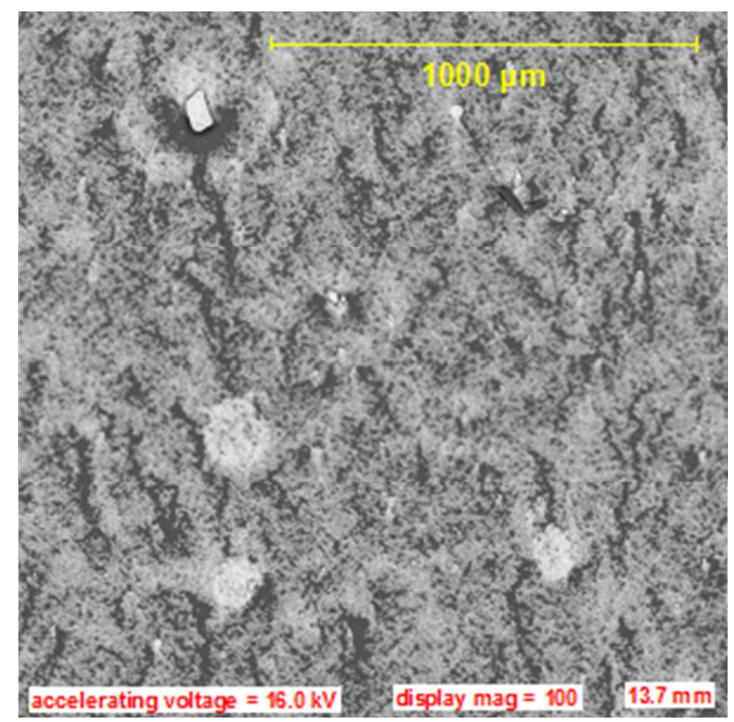

Figure 14. SEM image of ZNO film annealed at $250^{\circ} \mathrm{C}$.

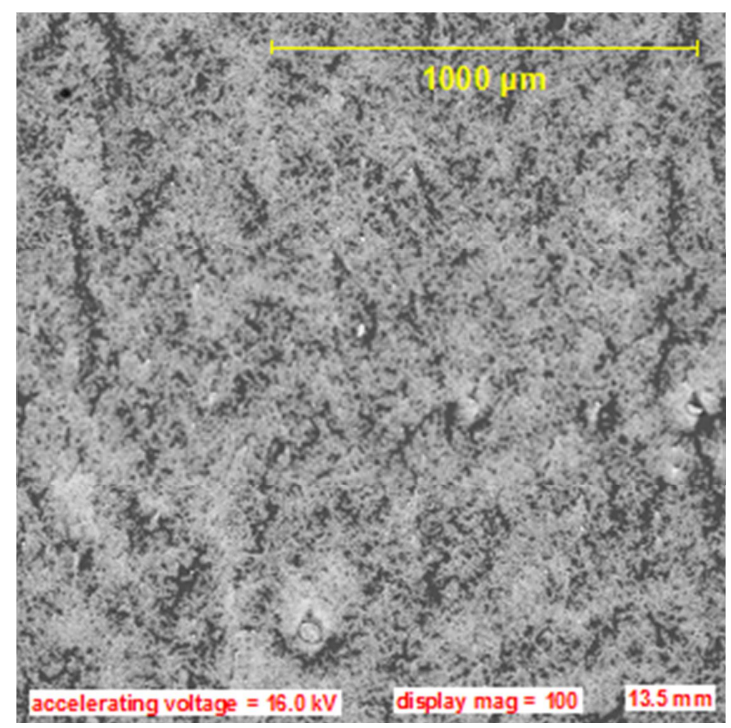

Figure 15. SEM image of ZNO film annealed at $350^{\circ} \mathrm{C}$.

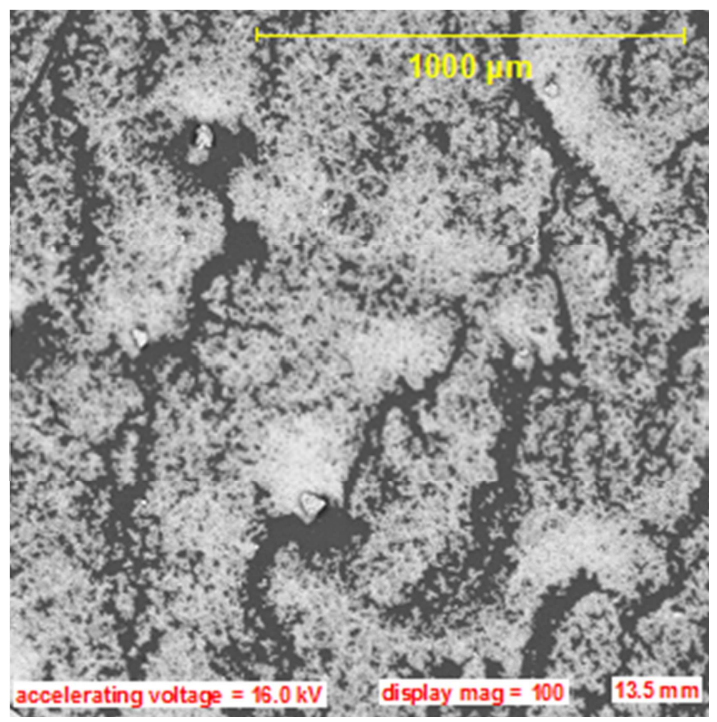

Figure 16. SEM image of ZNO film annealed at $450^{\circ} \mathrm{C}$.

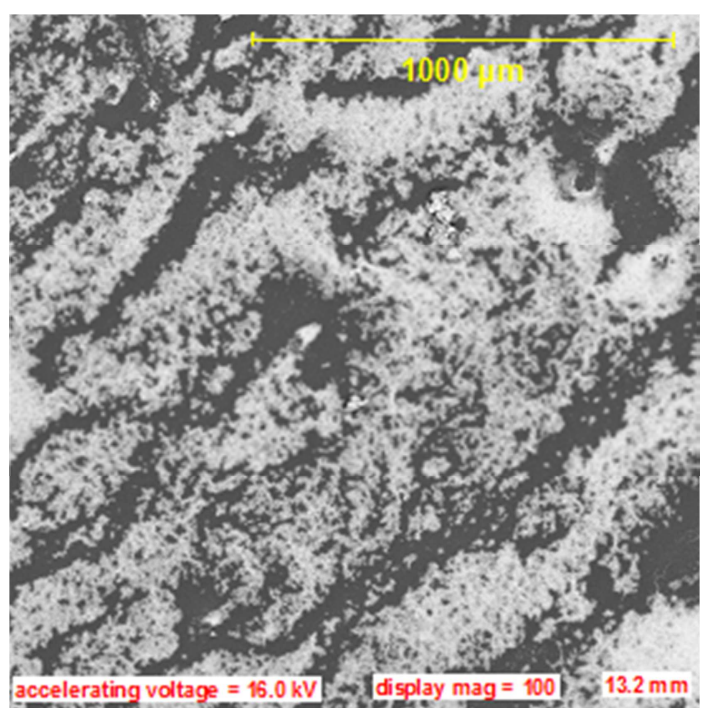

Figure 17. SEM image of ZNO film annealed at $550^{\circ} \mathrm{C}$.

\section{Result}

It was deduced that as the annealing temperature increases there is increase in absorption of photon energy. It also shows that transmission increases as the wavelength increases and decreases with increases in annealing temperature. As the annealing temperature increases the absorption increases and as the wavelength increases the absorption decreases. Zinc Oxide thin films prepared on glass substrate by spin coating process and annealed at different temperatures from $150^{\circ} \mathrm{C}$ to $600^{\circ} \mathrm{C}$ step of $50^{\circ} \mathrm{C}$. It was deduced that annealing temperature affects the morphological and optical properties of the $\mathrm{ZnO}$ thin films. The transmission spectrums of the films were recorded by UV-VIS Spectrophotometer. The films showed high transparency in the visible region. Extinction coefficients were calculated. The extinction coefficient showed some variation with rise in annealing temperature of $\mathrm{ZnO}$ films. The Optical energy band gap values were obtained by plot of $(\alpha h v)^{2}$ versus $h v$. The value of band gaps agrees approximately with that of bulk $\mathrm{ZnO}$. As the annealing temperature increases the band gap value decreases. SEM image of the samples results the increase in roughness as annealing temperature increases, this is possibly because of increase in grain size, so that band gap energy Eg decreases.

\section{Discussion}

Transmittance of zinc oxide decreases with increase in heating temperature. There is optical stability of zinc oxide film in the visible absorption spectrum from $400 \mathrm{~nm}$ to $700 \mathrm{~nm}$ this will make zinc oxide suitable as buffer layer in solar cells. Photon absorption at $600^{\circ} \mathrm{C}$ has a waveform nature and decreases gradually compared to others annealed at lower temperature. Extinction coefficient of zinc thin film at $600^{\circ} \mathrm{C}$ rises steadily and linearly in a transient manner compared to a more stabilized nature of others annealed at lower temperature. 


\section{Conclusions}

The morphology and the optical properties of zinc oxide were studied for unheated and heated thin films. The photon absorption upon heating zinc oxide was highest at $500^{\circ} \mathrm{C}$ in the visible spectrum. Extinction coefficient of zinc oxide at $500^{\circ} \mathrm{C}$ was the highest in the visible spectrum. The band gap energy decreases with increase in heating temperature from $4.03 \mathrm{eV}$ to $3.5 \mathrm{eV}$. An important observation was noted at $600^{\circ} \mathrm{C}$, that heating zinc oxide on a glass substrate near or above the glass substrate melting point leads to transient fluctuation in absorption of photon energy of zinc oxide. The shortcomings called for alternative substrate at higher annealing temperature above $500^{\circ} \mathrm{C}$. ASPEX 3020 Scanning Electron Microscope was used to study the morphology of the thin film and the results shows as the annealing temperature increases the roughness of the surface of zinc oxide thin film increases.

\section{References}

[1] M. Hadis, O. Umit Zno Oxide Fundamental, Materials and Device Technology (Weinheim: WILLY-VCH Verlag GmbH\& Co. 2009).

[2] S. Sanjeev, D. Kekuda 2015 Effect of Annealing Temperature on the Structural and Optical Properties of Zinc Oxide ( $\mathrm{ZnO})$ Thin Films Prepared by Spin Coating Process IOP Conf. Ser.: Mater. Sci. Eng. 73012149.

[3] S. Yusan, A. Bampaiti, S. Aytas, S. Erenturk, M. A. A Aslani Synthesis and structural properties of $\mathrm{ZnO}$ and diatomitesupported $\mathrm{ZnO}$ nanostructures. Ceram Int. 2016; 42: 21582163.

[4] A. F. Aktaruzzaman, G. L. Shaaarm, L. K. Mahgotra: Thin solid Films, 198 (1991), pp 67-74.

[5] K. G. Kanade, B. B. Kale, R. C. Aiyer, B. K. Das Effect of solvents on the synthesis of nano-size zinc oxide and its properties. Mater Res Bull. 2006; 41: 590-600.

[6] M. Sabbaghan, A. S Shahvelayati, S. E Bashtani Synthesis and optical properties of $\mathrm{ZnO}$ nanostructures in imidazoliumbased ionic liquids. Solid State Sci. 2012: 14: 1191-1195.

[7] E. Darezereshki, M. Alizadeh, F. Bakhtiari, M. Schaffie A novel thermal decomposition method for the synthesis of $\mathrm{ZnO}$ nanoparticles from low concentration $\mathrm{ZnSO} 4$ solutions. Appl Clay Sci. 2011: 54: 107-111.

[8] H. Wang, C. Li, H. Zhao, R Li, J. Liu Synthesis, characterization, and electrical conductivity of $\mathrm{ZnO}$ with different morphologies. Powder Technol. 2013; 239: 266-271.

[9] W. L Suchanek Systematic study of hydrothermal crystallization of zinc oxide $(\mathrm{ZnO})$ nano-sized powders with superior UV attenuation. J Cryst Growth. 2009; 312: 100-108.

[10] A. Kołodziejczak-Radzimska, T. Jesionowski. Zinc OxideFrom Synthesis to Application: A Review. Materials 2014; 7 : 2833-2881.

[11] C. C. Chen, P. Liu, C. H Lu Synthesis and Characterization of nano-sized $\mathrm{ZnO}$ powders by direct precipitation method. Chem Eng J. 2008; 144: 509-513.
[12] O. Lupan, L. Chow, G. Chai, B. Roldan, A. Naitabdi Nanofabrication and characterization of $\mathrm{ZnO}$ nanorod arrays and branched microrods by aqueous solution route and rapid thermal processing. Mater Sci Eng B. 2007; 145: 57-66.

[13] C. Ravichandran, G. Srinivasan, C. Lenno Investigations on the structural and optical properties of $\mathrm{Li}, \mathrm{N}$ and $(\mathrm{Li}, \mathrm{N})$ codoped $\mathrm{ZnO}$ thin films prepared by sol-gel technique. Mater Sci Semicond Process. 2010; 13: 46-50.

[14] N. Brihi, Z. Takkouk, A. Bouaine Laser annealing effects on the structural, optical and magnetic properties of sputtered Zn0.95Co0.05O thin film. Mater Sci Eng B. 2007; 145: 610.

[15] M. A Gondal, AM Ilyas, T. A Fasasi, M. A Dastageer Synthesis of green $\mathrm{TiO} 2 / \mathrm{ZnO} / \mathrm{CdS}$ hybrid nano-catalyst for efficient light harvesting using an elegant pulsed laser ablation in liquids method. Appl Surf Sci. 2015; 357: 2217-2222.

[16] R. M Mohamed, D. McKinney, M. W Kadi, I. A Mkhalid Cobalt/zinc oxide hollow spheres: Visible light nanophotocatalysts. Ceram Int. 2016; 42: 2299-2305.

[17] S. He, X. Zou, Z. Sun, G. Teng Influence of precursor solution's concentration on double-layer $\mathrm{ZnO}$ structure and solar cell's performance. Mater Lett. 2013; 91: 258-260.

[18] E. M Flores, C. W Raubach, R. Gouvea, E. Longo, S. Cava Optical and structural investigation of ZnO@ZnS core-shell nanostructures. Mater Chem Phys. 2016; 173: 347-354.

[19] K. Nejati, Z. Rezvani, R. Pakizevand Synthesis of ZnO Nanoparticles and Investigation of the Ionic Template Effect on Their Size and Shape. Int Nano Lett. 2011; 1: 75-81.

[20] G. Nagaraju, S. Ashoka, P. Chithaiah, C. N Tharamani Surfactant free hydrothermally derived $\mathrm{ZnO}$ nanowires, nanorods, microrods and their characterization. Mater Sci Semicond Process. 2010; 13: 21-28.

[21] H. S Goh, R. Adnan, M. A Farrukh $\mathrm{ZnO}$ nanoflake arrays prepared via anodization and their performance in the photodegradation of methyl orange. Turkish J Chem. 2011; 35: 375-391.

[22] M. Zareie, A. Gholami, M. Bahrami, A. H Rezaei A simple method for preparation of micro-sized $\mathrm{ZnO}$ flakes. Mater Lett. 2013; 91: 255-257. e-ISSN: 2319-9849 p-ISSN: 23220049RRJCHEM | Volume 5 | Issue 2 | July, 2016.

[23] B. Kumar, K. Smita, L. Cumbal, A. Debut, R. N. Pathak Ionic Liquid Based Silica Tuned Silver Nanoparticles: Novel Approach for Fabrication. Synth Reac Inorganic Met NanoMetal Chem. 2016; 46: 1265-1271.

[24] T. Kawano, H. Imai. A simple preparation technique for shape-controlled zinc oxide nanoparticles: Formation of narrow size-distributed nanorods using seeds in aqueous solutions. Coll Surf A: Physicochem Eng Asp. 2008; 319: 130-135.

[25] Y. Matsushima, M. Matsumoto, K. Maeda, T. Suzuki Photoluminescence and electroluminescence of $\mathrm{ZnO}: \mathrm{Zn}$ layers prepared by a chemical vapor deposition method with ethanol addition. Mater Sci Eng B. 2007; 145: 1-5.

[26] R. B. Kale Morphological evolution of hydrothermally derived $\mathrm{ZnO}$ nano and microstructures. Opt-Int J Light Electron Opt. 2016; 127: 4621-4624. 
[27] Y. Li, G. Li, S. Wang, H. Gao, Z. Tan Preparation and characterization of nano- $\mathrm{ZnO}$ flakes prepared by reactive ion exchange method. J Therm Anal Calorim. 2009; 95: 671-674.

[28] S. Al-Heniti, A. Umar, P. Singh, A. Sayari, A. Al-Hajry Nanocrystalline $\mathrm{ZnO}$ flakes for photovoltaic device applications. Adv Sci Lett. 2010; 3: 543-547.

[29] A. K. Zak, W. H. A Majid, M. E Abrishami, R. Yousefi X-ray analysis of $\mathrm{ZnO}$ nanoparticles by Williamson-Hall and sizestrain plot methods. Solid State Sci. 2011; 13: 251-256.

[30] S. ILican, Y. Caglar, M. Caglar, Preparation and characterization of $\mathrm{ZnO}$ thin films deposited by sol-gel spin coating method. Journal of Optoelectronics and advanced Materials 2008 Vol. 10, No. 10. $2578-2583$.

[31] I. K Kumar, P. R. Balachandraand Synthesis and characterization of nano zinc oxide by gel spin coating. Recent Research in Science and Technology 2011, 3 (3): 4852 .

[32] Shakti, Nanda, P. S. Gupta, Structural and Optical Properties of Sol-gel Prepared ZnO Thin Film. Applied Physics Research 2010 Vol. 2, No. 1. 19-28.

[33] J. Tauc, 1970. The optical properties of solids (North-Holland, Amsterdam, 1970). 